\title{
Erosão marginal e sedimentação no rio Paraguai no município de Cáceres (MT)
}

\author{
Aguinaldo Silva ${ }^{1}$, Edvard Elias de Souza Filho ${ }^{2}$ \& Sandra Mara Alves da Silva Neves ${ }^{3}$
}

\begin{abstract}
Resumo A bacia do rio Paraguai vem sendo alvo de ocupação intensa nos últimos anos e seu canal tem sofrido modificações em sua dinâmica. A pesquisa teve como objetivo investigar a dinâmica das margens do rio Paraguai por um período de dezenove anos. Para realização do estudo foi realizado o cruzamento de imagens de satélite TM Landsat 5 do ano de 1984 e ETM Landsat 7 de 2003, pois o método de pinos utilizado geralmente para o monitoramento da erosão marginal não é adequado para o rio Paraguai em virtude da sua dinâmica e composição das margens. Os estudos de erosão marginal demonstraram que o canal apresenta mobilidade relativamente alta em ambos os segmentos ( $2,3 \mathrm{~m} / \mathrm{ano})$. O monitoramento da erosão marginal é extremamente importante quando se tem áreas urbanas localizadas próximas a rios. Como é o caso da cidade de Cáceres localizada na margem esquerda do rio Paraguai e que vem sofrendo os impactos (sociais e econômicos) causados pela erosão marginal. Além desse fator o monitoramento da erosão marginal permite observar a dinâmica do canal ocasionado pela erosão marginal.
\end{abstract}

Palavras-chave: dinâmica fluvial, erosão marginal, rio Paraguai.

\begin{abstract}
Bank erosion and sedimentation in the Paraguay River, Cáceres (MT), Brazil. The Paraguay River Basin has been intensively occupied since the 1970 years and its channel dynamic has been changing. The dynamics of the fluvial corridor's margins was studied, tends as objective evaluating the erosion for a period of nineteen years, using the crossing of images of satellite TM Landsat 5 of the year of 1984 and ETM Landsat 7 de 2003, because the method of pins generally used for monitoring riverbank erosion is not good for the Paraguay river because of their dynamics and composition of the banks. Considering the bank erosion, the channel showed a relatively high mobility in both segments $(2,3 \mathrm{~m} / \mathrm{y})$. The monitoring of riverbank erosion is extremely important when it have urban areas located near rivers. Cáceres city is located on the left bank of the river Paraguay and has suffered the impacts (social and economic) caused by riverbank erosion. Besides, the monitoring of riverbank erosion allow observe the dynamics of the channel caused by riverbank erosion.
\end{abstract}

Keywords: fluvial dynamics, marginal erosion, Paraguay River.

INTRODUÇÃO O rio Paraguai tem suas nascentes no Planalto dos Parecis no Estado de Mato Grosso. Fluindo de norte para sul, o rio percorre uma extensão de $2.612 \mathrm{~km}$, dos quais $1693 \mathrm{~km}$ em território brasileiro, até sua confluência com o rio Paraná na altura da cidade de Corrientes, na Argentina. Sua bacia de drenagem totaliza $1.095 .000 \mathrm{~km}^{2}$, compreendendo os estados de Mato Grosso e Mato Grosso do Sul e parte dos territórios da Bolívia, do Paraguai e da Argentina (Fig. 1).

Os estudos relativos ao alto rio Paraguai não são abundantes e em sua maior parte a abordagem é regional, como é o caso do Plano de Conservação da Bacia do Alto Paraguai-Pantanal (Ministério dos Recursos Hídricos e da Amazônia Legal 1997), cujo objetivo foi a realização de um levantamento das potencialidades e riscos da Bacia do Alto Paraguai, e o Programa de Ações Estratégicas para o Gerenciamento Integrado do Pantanal e da Bacia do Alto Paraguai (ANA 2004). Os únicos trabalhos que abordaram a geomorfologia do rio foi o de Souza (2004), que realizou um estudo do canal fluvial, no segmento entre Cáceres e a Estação Ecológica Taiamã, abordando a dinâmica do corredor fluvial, Silva $(2006,2007,2008)$ realizou estudo sobre padrão de canal do rio Paraguai e mais recentemente a compartimentação geomorfológica do rio Paraguai entre a foz do rio Sepotuba e a Estação Ecológica do Taiamã e Assine \& Silva (2009) que abordou os estilos fluviais do rio Paraguai na parte norte do Pantanal na região de Cáceres.

Em relação ao monitoramento da erosão marginal do rio Paraguai destaca-se Souza et al. (2007) que utilizou a metodologia de pinos no monitoramento da erosão marginal no rio Paraguai, Silva et al. (2007 e 2008) que utilizou estacas como método para monitoramento da erosão marginal de um trecho do rio Paraguai localizado a montante do município de Cáceres e mais recentemente a utilização de geotecnologias para quantificação da erosão marginal no Bairro São Miguel na cidade de Cáceres.

Os estudos sobre erosão marginal assumem

1 - Universidade Federal de Mato Grosso do Sul (UFMS), Campus Pantanal, Departamento de Ciências do Ambiente/Geografia, Corumbá (MS), Brasil. E-mail: aguinald_silva@yahoo.com.br

2 - Universidade Estadual de Maringá (UEM), CCH, DGE/GEMA, Maringá (PR), Brasil. E-mail: edvardmarilia@wnet.com.br

3 - Universidade do Estado de Mato Grosso, Campus Universitário de Cáceres, Departamento de Geografia, Cáceres (MT), Brasil.

E-mail: ssneves@unemat.br 


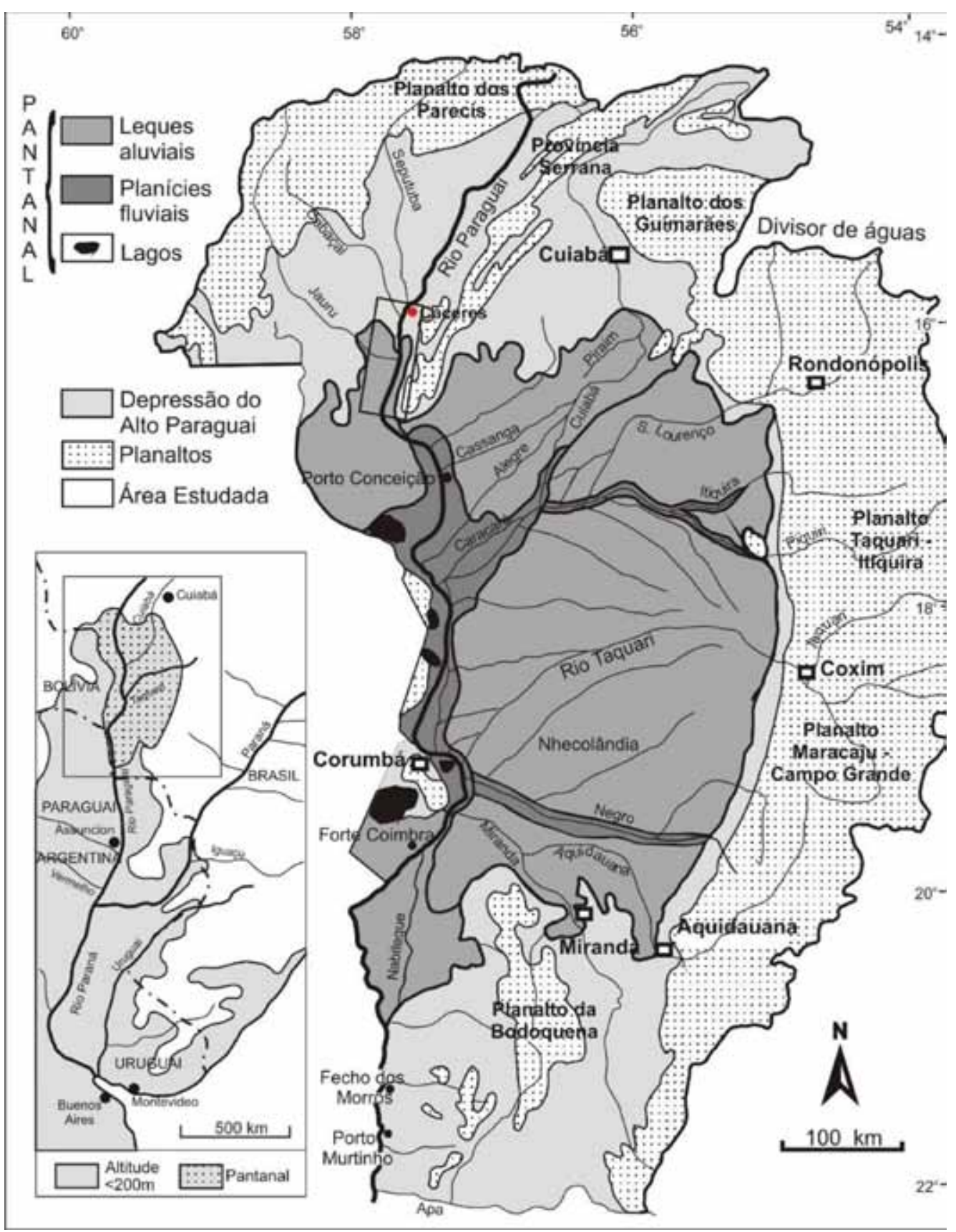

Figura 1 - Mapa da Bacia do Alto Paraguai, em destaque (quadro preto) a área estudada. (modificado de Assine et al. 2004).

um papel muito importante dentro do planejamento urbano e ambiental, uma vez que são registrados prejuízos financeiros e impactos sociais negativos representados pela perda de terrenos cultiváveis em áreas agrícolas, desvalorização das terras ribeirinhas, comprometimento ou destruição de estruturas de engenharia próximas ao leito do canal fluvial (estradas, pontes, barragens, diques, casas, torres de transmissão de energia, etc.)

No caso da região estudada já possível observar alguns impactos ocasionados pela erosão marginal como, por exemplo, no Bairro São Miguel, próximo a BR 174 e também na fazenda Descalvados localizada a $150 \mathrm{~km}$ a jusante de Cáceres.
Os resultados deste trabalho podem, igualmente, ajudar no entendimento do sistema e auxiliar em projetos importantes para o desenvolvimento da região como a Hidrovia Paraguai - Paraná, uma das principais preocupações dos ambientalistas como, por exemplo, Bucher \& Huszar 1995; Hamilton 1999; Gottgens et al. 2001 e desta forma expandir a contribuição científica sobre questões chaves relativas à evolução natural da paisagem e a dinâmica dos sistemas fluviais na região do Pantanal Mato-grossense. Desta forma, este trabalho tem por objetivo avaliar a partir de imagens de satélites a erosão marginal e a sedimentação que ocorre ao longo do rio Paraguai na região de Cáceres-MT. 
ÁREA ESTUDADA A área investigada está situada na região de Cáceres, e compreende o segmento localizado entre a foz do rio Cabaçal e localidade conhecida como Morro Pelado, entre as coordenadas $15^{\circ} 45^{\prime}$ e $16^{\circ} 35^{\prime}$ de latitude sul e $57^{\circ} 40^{\prime}$ e $58^{\circ} 15^{\prime}$ de longitude oeste (Fig. 2).

O clima da região é o tropical, com duas estações bem definidas (seca no inverno e úmida no verão), e temperatura média anual de $25^{\circ} \mathrm{C}$ e a precipitação média anual é de $1.323 \mathrm{~mm}$. O período de janeiro a março é o mais úmido, com média histórica de 200,83 $\mathrm{mm}$ e o período entre setembro e outubro é o de maior índice de radiação solar, com temperatura média de $25,1^{\circ} \mathrm{C}$ e $27,1^{\circ} \mathrm{C}$ e de mais baixa precipitação, com média de $51,55 \mathrm{~mm}$ e $82,15 \mathrm{~mm}$.

De acordo com Silva et al. (2007) e Assine \& Silva (2009), o trecho estudado tem como característica comum o fato de que a planície se encontra embutida em um vale entrincheirado, escavado em depósitos mais antigos de idade pleistocênica, com terraços marginais cujas alti-
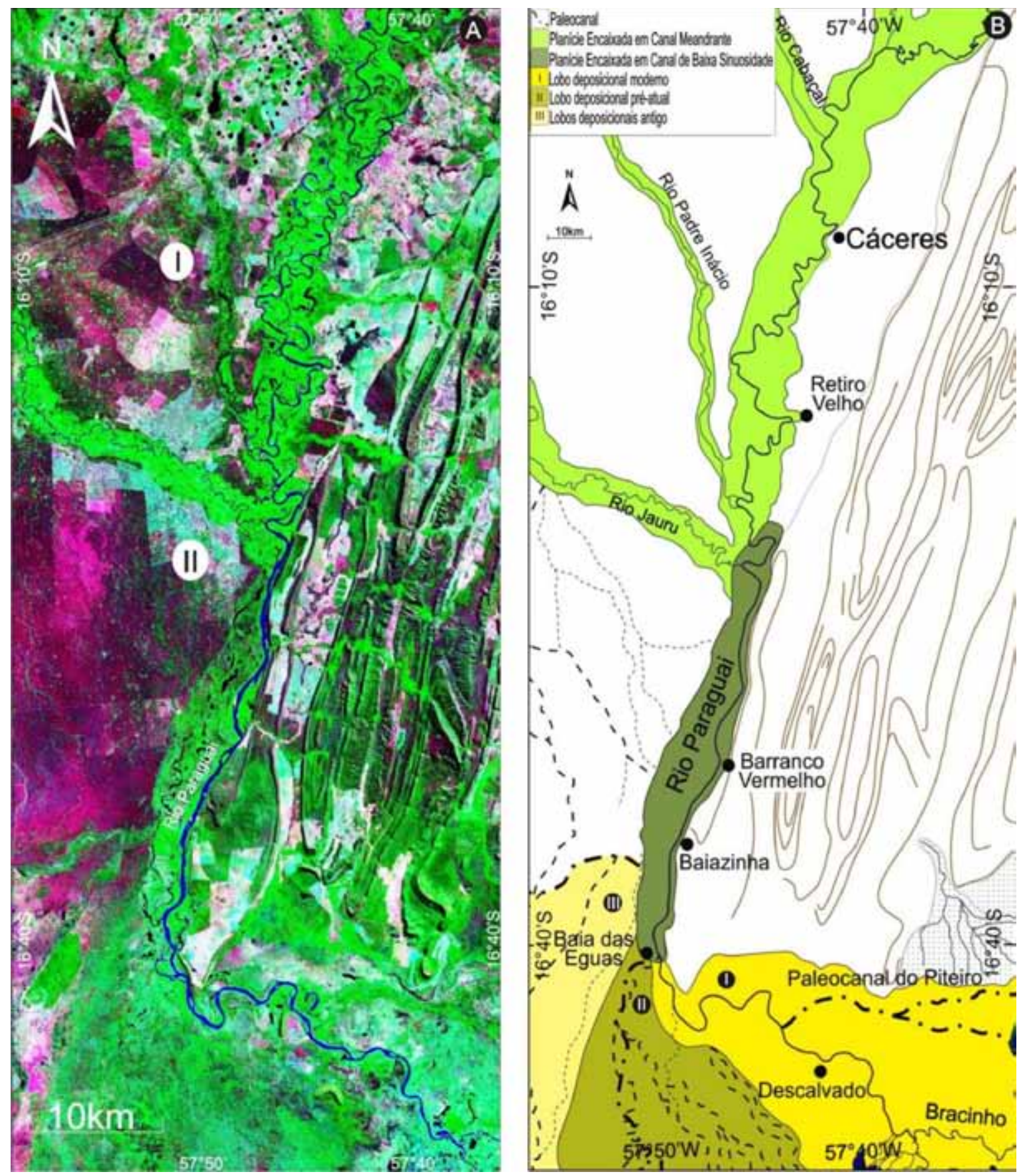

Figura 2 - (A) Imagem de satélite da área estudada I) segmento superior e (II) segmento inferior (composição falsa cor RGB 742 com pixel reamostrado para $15 \mathrm{~m}$ a partir da fusão com a banda 8; fonte: mosaico NASA Geocover Circas 2000) e (B) Compartimentação geomorfológica da planície do rio Paraguai na área estudada. 
tudes decrescem para jusante. A bacia de drenagem tem forma assimétrica, uma vez que os afluentes da margem direita são mais longos que os da margem esquerda.

No compartimento definido por Silva et al. (2007), entre a foz do rio Sepotuba e a foz do rio Jauru, a planície fluvial possui extensão de $71 \mathrm{~km}$ e largura média de $6 \mathrm{~km}$. Neste segmento, a planície de inundação apresenta inúmeras barras em pontal e lagoas em meandros abandonados, e o rio meandra pela planície com largura média de $150 \mathrm{~m}$ e índice de sinuosidade acima de 1.5 .

Ainda de acordo com Silva et al. (2007), compreendendo o trecho da foz do rio Jauru até a altura da localidade conhecida como Baía das Éguas, possui extensão de $35 \mathrm{~km}$ e planície de inundação com aproximadamente $4 \mathrm{~km}$ de largura. Neste segmento o canal apresenta baixo índice de sinuosidade $(1,1)$, largura média de $200 \mathrm{~m}$, barras laterais e várias ilhas. Já a planície de inundação apresenta canais menores com alta sinuosidade, de natureza reliquiar, mas ainda ativos durante as cheias. Destaca-se que a planície é assimétrica uma vez que o rio corre nas proximidades de sua margem esquerda, ladeando terrenos pré-cambrianos da Província Serrana ou, em alguns locais, estreitos terraços de depósitos aluviais quaternários.

Em recente trabalho desenvolvido por Assine \& Silva (2009) o rio Paraguai atravessa domínios geológicos e geomorfológicos distintos na bacia do Pantanal. Em virtude desse fator apresenta uma compartimentação muito complexa. Na região de Cáceres, em terras baixas da Depressão do Alto Paraguai, o rio Paraguai se apresenta como um rio aluvial, uma vez que é responsável pelo processo de agradação num cinturão de meandros embutido num vale entrincheirado em depósitos aluviais mais antigos. Esta configuração está intimamente associada à existência do leque do Paraguai, que vem sendo construído pelo rio Paraguai na entrada da planície sedimentar do Pantanal, onde o rio deflete para leste.

MATERIAL E MÉTODOS As formas de avaliação da erosão marginal foram discutidas por Borges (2004) e elas incluem métodos diretos e indiretos. Os métodos diretos são aqueles em que a taxa erosiva é obtida por meio de monitoramento de campo, que pode ser efetuado por meio de pinos, estacas ou perfilagens sucessivas (Hooke 1980). Os métodos indiretos são aqueles em que o deslocamento das margens é calculado a partir de dados cartográficos ou de sensoriamento remoto. Neste caso são comparados produtos cartográficos, fotografias aéreas ou imagens orbitais de diferentes idades e a posição das margens em uma data é comparada à posição em outra.

Para monitoramento da erosão marginal no rio Paraguai, utilizou-se o método indireto, pois o método direto em que se utiliza pinos de ferro com $1 \mathrm{~m}$ de comprimento e $5 \mathrm{~mm}$ de diâmetro, inseridos horizontalmente na face das margens, posicionados em seqüência vertical em cada ponto monitorado, adaptado para os rios tropicais por Fernandes (1990) não apresentou um resultado satisfatório em decorrência da própria dinâmica dos rios tropicais. De acordo com Souza (2004) é necessário que juntamente com o método de pinos seja adotado outros métodos para o monitoramento da erosão marginal.

Em relação a área estudada o compartimento I apresenta-se sinuoso em decorrência do padrão meandrante do rio Paraguai neste setor, neste caso o monitoramento das margens côncavas onde ocorre o predomínio da erosão, torna-se difícil a partir do método de pinos, pois de acordo com Souza (2007) a maioria dos pinos fixados nesta margem foram perdidos em decorrência da erosão prejudicando os resultados.

Em decorrência do método de pinos não oferecer um resultado satisfatório, foi utilizada a comparação de imagens orbitais de diferentes datas. Para isso foram utilizadas duas imagens da satélite da estação seca, com intervalo de tempo de 19 anos entre uma e outra: 1) TM, LANDSAT 5, de 08/08/1984; e 2) ETM, LANDSAT 7, de 30/07/2003.

$\mathrm{O}$ tratamento das imagens foi realizado através do software SPRING (Sistema de Processamento de Informações Georreferenciadas). O tratamento de imagens digitais nada mais é do que a análise e a manipulação de imagens através de técnicas computacionais, com finalidade de identificar e extrair informações da imagem sobre fenômenos ou objetos do mundo real, e transformar a imagem de tal modo que as informações radiométricas contidas nela sejam mais facilmente discrimináveis pelo analista (Mascarenhas \& Velasco, apud Moreira 2003).

Para o cruzamento do plano de informação, foi utilizado o Software ArcGis 9.0. A área de canal classificada em cada cena foi dividida em dois segmentos (superior e inferior) e a superposição delas em arquivo georeferenciado permitiu o cálculo da área erodida e da área de deposição para o período entre 1984 e 2003 em ambos os segmentos. O intervalo de tempo entre a obtenção das duas imagens (19 anos) permitiu o cálculo da taxa de erosão anual.

RESULTADOS Os principais fatores condicionantes da erosão em margens fluviais estão associados à estrutura da margem e às condicionantes hidrodinâmicas nas proximidades destas (Fernandez 1990). Dentre estes últimos, a variação do nível do rio é considerada como um dos fatores mais importantes para o controle da erosão marginal, pois é responsável pela atuação das forças de origem fluvial sobre os materiais das margens, ou seja, as ondas e as correntes. As correntes atuam promovendo junto às margens a corrasão, e a ação mais abrasiva nas margens são ocasionadas pela ação do fluxo e dos ventos.

A variação do nível do rio ao longo de um ciclo hidrológico e a energia disponibilizada determina o alcance destrutivo ocasionados pela ação do fluxo e dos ventos. A energia é proporcional a velocidade de fluxo, que é a variável mais importante para a definição da competência de um canal.

Desta forma quanto maior a velocidade, maior o tamanho das partículas transportadas, tornando a composição granulométrica das margens uma variável secundária no estudo da erosão marginal, principalmente em margens côncavas.

As margens com altas taxas de erosão estão todas situadas em locais de alta velocidade de fluxo de 
água. Tais margens apresentam face íngreme, e contato direto com a água. Apesar de que certo tipo de barranco apresente baixo índice erosivo, é evidente que a sua estrutura também está comprometida, devido ao alto índice de erosão localizado na sua base.

A distribuição da erosão marginal pode variar, notadamente, de um ponto para outro da margem porque as características morfológicas e sedimentológicas do talude podem variar e, além disso, quase sempre o ângulo de incidência da corrente na margem varia de um local para outro devido ao traçado do rio.

$\mathrm{Na}$ área de estudo, as margens do rio Paraguai exibem diversos tipos de feições erosivas conforme pode ser observado na figura 3 . As margens em posição vertical, e os sedimentos acumulados em suas bases indicam que há erosão ativa ao longo do rio Paraguai.

No caso estas formas são atribuídas à queda de blocos e a desmoronamentos causados pelo solapamento da parte baixa da margem, resultante da corrosão da ação hidráulica da água, e da ação das ondas provocadas pelos barcos.

O rio Paraguai na área estudada apresenta diversos estilos de padrão de canal. Em relação ao primeiro segmento da foz do rio Cabaçal até a confluência com o rio Jauru o canal é meandrante de alta sinuosidade $(1,5)$. Nesse tipo de canal o material é erodido da parte côncava, externa, onde ocorre se concentram as maiores velocidades de fluxos e transportado para jusante e depositado na parte convexa, interna onde vai formar barras em pontal. Na figura 4 é possível observar a alteração no canal em decorrência do corte de meandro (cut off). Esses cortes de meandros, características de sistema fluvial meandrante provoca no canal alterações como declividade, capacidade, competência, provocando um novo ajuste no sistema.

No segmento seguinte até as proximidades do Morro Pelado o canal apresenta baixa sinuosidade (Fig. 5) com alguns trechos retilíneos. Neste segmento em decorrência das características das margens os processos erosivos são menos intensos, quando comparados ao segmento superior. $\mathrm{Na}$ margem direita do canal ocorre um predomínio maior de argila o que tornar a margem mais estável e na margem direita em decorrência do canal ser ladeado por rochas pré-cambrianas.

Ao longo do segmento inferior é possível observar a partir de imagens de satélites a presença de barras centrais e transversais, o que caracteriza esse segmento localizado na entrada do pantanal, a atual área de deposição do alto rio Paraguai.

Em decorrência da variação no estilo e na dinâmica do canal, a erosão marginal e a sedimentação ao longo do canal tende a variar.

Nos dois segmentos analisados o incremento da carga sedimentar depositada pode ser observada nas formas de barras. Essas formas deposicionais remodelam o canal fazendo com que o mesmo ao longo do tempo altere sua forma e traçado. Como os processos erosivos e sedimentares se intensificando podem provocar o estreitamento do canal e a sua retilinização em alguns pontos diminuindo sua extensão longitudinalmente e desta forma sua declividade e competência.

A partir do cruzamento com imagens de satélite
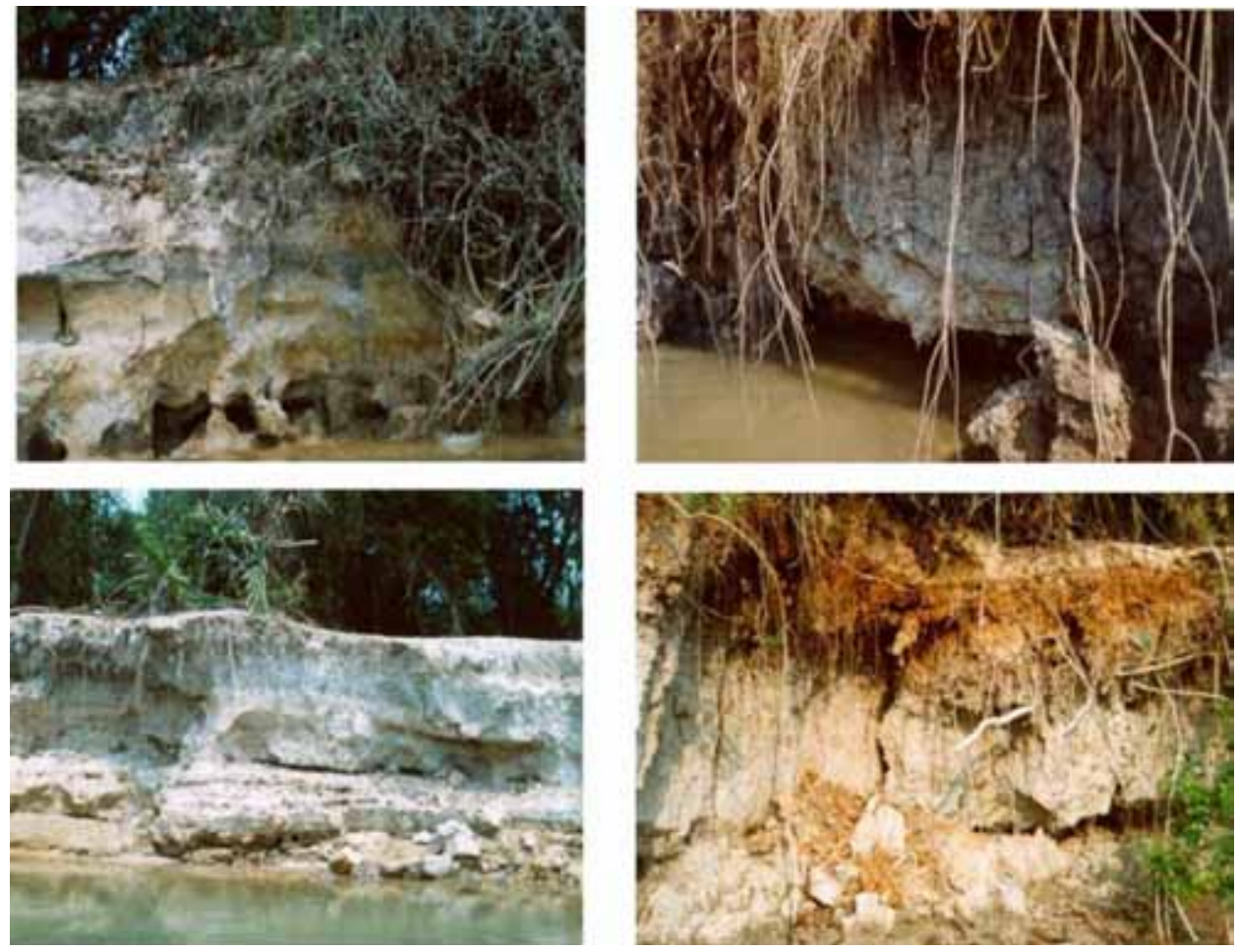

Figura 3 - Formas erosivas no rio Paraguai no segmento superior, onde é possivel observar a base das margens solapadas ocasionando a queda de blocos. 

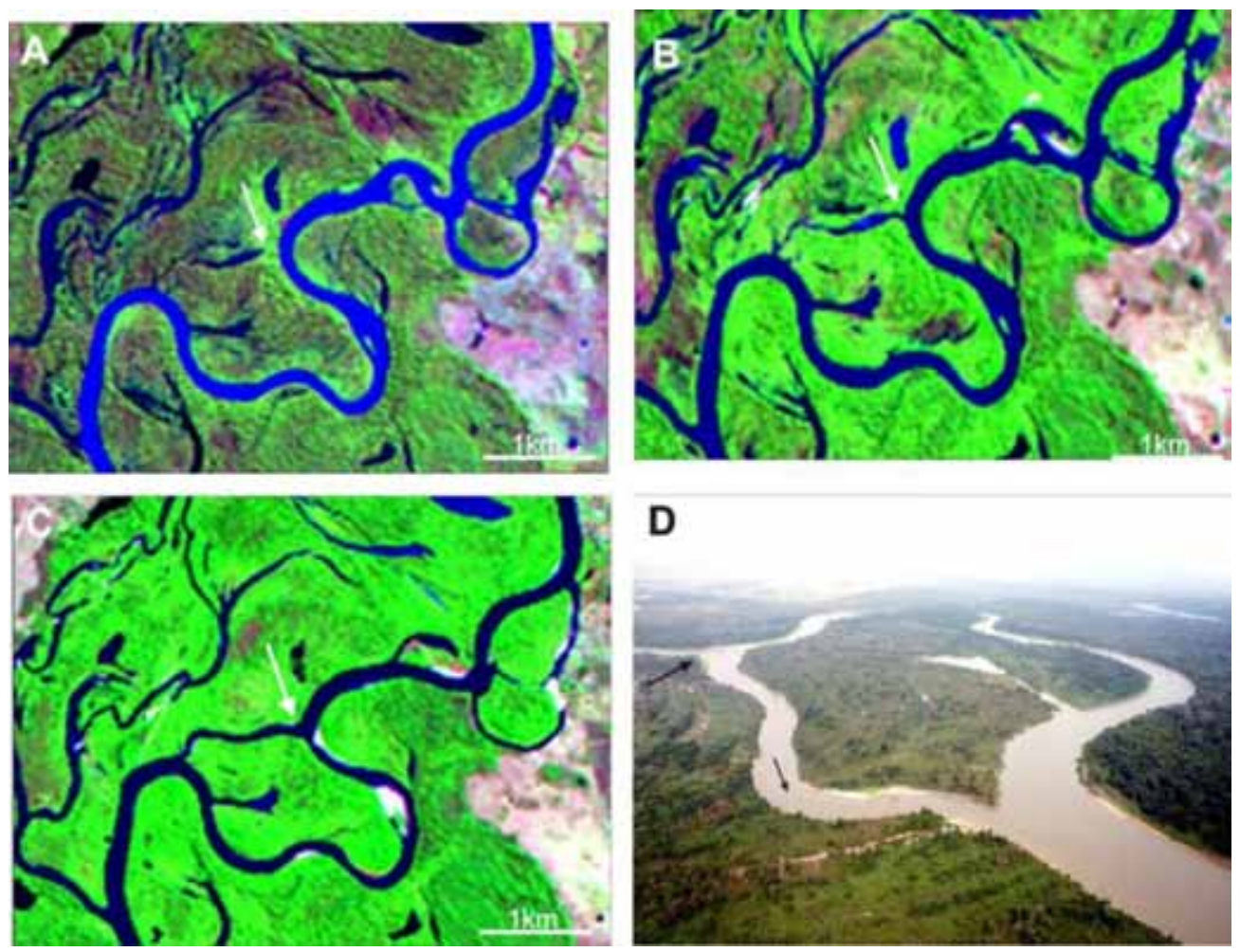

Figura 4 - Imagem de satélite Landsat 5 (R5G4B3) mostrando as alterações ocorrida no canal em decorrência da erosão marginal. Na figura A (1986) B (1996) e C (2005) é possivel observar através da seta a mudança do canal até o abandono do canal principal. Na figura (D) foto obliqua é possível verificar o novo canal que evoluiu a partir de processos erosivos na margem côncava.

foi possível obter os seguintes valores para a área erodida, depositada, taxas de erosão e de deposição de todo o segmento estão expostas na tabela 1.

Os valores apresentados na tabela 1 permitem verificar que a erosão marginal foi maior no segmento superior em decorrência da característica do rio, que apresenta padrão meandrante onde ocorre o predomínio da erosão na margem côncava, diferente do segmento inferior onde o canal apresenta baixa sinuosidade, tendendo para retilíneo. Tais valores são maiores que os obtidos para o rio Paraná, uma vez que, o levantamento feito para as Ilhas Mutum e Porto Rico, usando imagens TM permitiu avaliar em $1,23 \mathrm{~m} /$ ano no período de 1986 a 1996, e $0,91 \mathrm{~m} /$ ano no período de 1996 a 2000, período sob influência das barragens (Souza Filho \& Stevaux 2004).

Para a avaliação da taxa de recuo médio das margens foi utilizado o valor de $81,4 \mathrm{~km}$ para o segmento superior, $31,5 \mathrm{~km}$ para o segmento inferior e $112,9 \mathrm{~km}$ para o segmento total, os resultados estão exibidos na tabela 2 .

Os dados exibidos na tabela 2 permitem verificar que no período o canal apresenta uma mobilidade relativamente alta, com média anual superior a 2 metros e à primeira vista há indicação de redução da sua largura. Contudo, as cenas foram obtidas em diferentes situações de nível fluviométrico em Cáceres $(2,44 \mathrm{~m}$ em 08/08/1984 e 1,74 m em 30/07/2003) o que explica

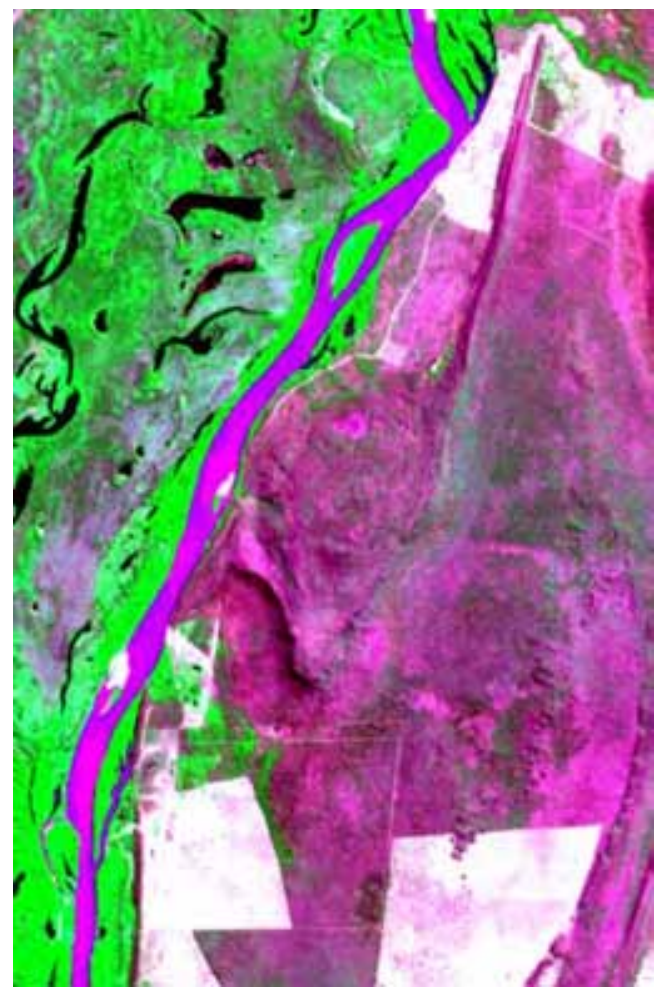

Figura 5 - Imagem de satélite de parte do segmento inferior, onde é possivel observar a presença de ilhas, barras transversais e a baixa sinuosidade do canal. 
os valores elevados de barras emersas.

A atuação dos processos erosivos ocorreu principalmente na margem direita do rio Paraguai, enquanto a deposição ocorreu principalmente junto à margem esquerda.

A tendência de domínio de erosão na margem direita indica que o rio Paraguai provavelmente está sujeito à efeito de tectônica recente, que teria provocado um basculamento para oeste, fazendo com que os processos erosivos fossem mais atuantes naquela margem, conforme discutido por Souza Filho \& Silva (2005).

O trabalho realizado por Souza (2004), analisando a erosão marginal do rio Paraguai, através do sistema de pinos, obteve valores distintos para os diferentes pontos amostrados no segmento superior e inferior no período em que foi realizado o monitoramento (setembro de 2001 a agosto de 2002), as seções foram estabelecidas de $10 \mathrm{em} 10 \mathrm{~km}$ a partir de Cáceres, como pode ser observado na tabela 3 .

Os pontos amostrados pela autora apresentaram valores inferiores aos obtidos pela análise das imagens e o pequeno número de pontos não permite uma comparação segura entre os dois segmentos.

DISCUSSÃO DOS RESULTADOS A velocidade da água é um fator importante na determinação da capacidade erosiva, transporte e deposição de sedimentos. A alta velocidade da água resulta geralmente em erosão e transporte, enquanto que a deposição ocorre quando a velocidade de fluxo diminui.

A declividade do leito é um fator que controla a velocidade, uma subida do substrato rochoso pode favorecer a erosão. Desta forma com o aumento do gradiente consequentemente irá ocorrer um aumento da erosão e o entalhe do canal. Se ocorrer uma diminuição do gradiente provocará uma diminuição da erosão e um aumento na sedimentação.

Num comparativo entre rios aluviais e rios rochosos, explica-se que nos rios aluviais, quando a quantidade de sedimentos é superior à sua capacidade de transporte, ocorre o assoreamento. Nos rios rochosos ainda não se tem uma conclusão definida, visto que é necessária uma observação contínua durante longos períodos de tempo, na fase alta e na fase baixa das águas.

A erosão marginal pode ser definida como o recuo linear das margens, resultante da remoção dos materiais que a constituem pela ação fluvial (correntes, ondas) ou por forças de origem externa, como a precipitação (Fernandes 1990).

Para Hooke (1979), a evolução da erosão marginal acontece em curto período de tempo, comparativamente a muitos outros processos geomorfológicos, mostrando assim a importância de conhecimentos sobre o grau de erosão marginal, a fim de possibilitar planejamento adequado no que concerne ao uso e ocupação das margens.

O fenômeno de alargamento e migração dos canais fluviais é facilitado e acompanhado da erosão marginal. Os processos de erosão das margens estão entre os elementos mais dinâmicos da paisagem e o entendimento do seu mecanismo de atuação é fundamental para a explicação da evolução dos diversos elementos da dinâmica fluvial.

A erosão marginal tem uma grande importância econômica em decorrência da perda de áreas cultiváveis, na proteção de rodovias construídas próximo ao

Tabela 1 - Taxa de erosão e deposição do segmento superior e inferior.

\begin{tabular}{ccccc}
\hline \multirow{2}{*}{ SEGMENTO } & \multirow{2}{*}{ EROSÃO $\mathrm{M}^{2} .10^{3}$} & $\begin{array}{c}\text { TAXA DE EROSÃO } \\
\mathrm{M}^{2} .10^{3} / \mathrm{ANO}\end{array}$ & DEPOSIÇÃO $\mathrm{M}^{2} .10^{3}$ & $\begin{array}{c}\text { TAXA DE DEPOSIÇÃO } \\
\mathrm{M}^{2} .10^{3} / \mathrm{ANO}\end{array}$ \\
\hline SUPERIOR & 3.845 & 202,4 & 5.073 & 267,0 \\
INFERIOR & 1.116 & 58,7 & 1.827 & 96,2 \\
TOTAL & 4.961 & 261,1 & 6.900 & 363,2 \\
\hline
\end{tabular}

Tabela 2 - Avaliação do recuo da margem direita e de sua taxa anual, e do avanço da margem esquerda e de sua taxa no periodo entre 1984 e 2003.

\begin{tabular}{ccccc}
\hline SEGMENTO & ÁREA ERODIDA $\left(\mathrm{M}^{2} \cdot 10^{3}\right)$ & $\begin{array}{c}\text { COMPRIMENTO DO } \\
\text { SEGMENTO(KM) }\end{array}$ & $\begin{array}{c}\text { EROSÃO } \\
(\mathrm{M})\end{array}$ & TAXA DE EROSÃO (M/ANO) \\
\hline SUPERIOR & 3.845 & 81,4 & 47,4 & 2,5 \\
INFERIOR & 1.116 & 31,5 & 35,4 & 1,9 \\
TOTAL & 4.961 & 112,9 & 43,9 & 2,3 \\
\hline
\end{tabular}

Tabela 3 - Valores de recuo da margem em diferentes pontos do rio Paraguai Superior, obtidos pelo método dos pinos (modificado de Souza 2004).

\begin{tabular}{cccccccccccccc}
\hline COMPARTIMENTO & \multicolumn{1}{c}{ SUPERIOR } \\
\hline SEÇÃO & 1 & 2 & 3 & 4 & 5 & 6 & 7 & 8 & 9 & 10 & 11 & 12 \\
VALOR EROSÃO $(\mathrm{cm})$ & 14 & 44 & 79 & 20 & 80 & 16 & 25 & 22 & -- & 60 & 20 & -- \\
VALOR MÉDIO/ANO & 15,3 & 48 & 86,2 & 21,8 & 87,3 & 17,5 & 27,3 & 24 & --- & 65,5 & 21,8 & --- \\
\hline
\end{tabular}


canal fluvial, na complementação de estudos de assoreamento em reservatórios. Na figura 6 pode ser observado as consequências da erosão marginal na região de Cáceres, onde em decorrência desse processo, vem provocando perdas econômicas para a sociedade se tornando um problema social. O trabalho desenvolvido por Silva et al. (2008) utilizou imagens de alta resolução para quantificar os impactos causados pela erosão marginal em vários lotes residenciais no Bairro São Miguel.

A erosão fluvial pode ocorrer no leito, nas margens, ou nas cabeceiras dos rios. A erosão do leito é denominada erosão vertical e a das margens erosão marginal de acordo com Tuysuz (2005). O mesmo autor destaca que a erosão fluvial pode ser efetuada pela corrasão, pela ação hidráulica da água e pelo atrito dos materiais em transporte.

As propriedades mecânicas de uma margem estão relacionadas à composição granulométrica e no caso da resistência à erosão, a coesividade é uma variável importante. A coesividade dos sedimentos é proporcional ao teor de argila e desta forma quanto mais argilosa a margem, maior resistência ela oferece aos processos de remoção. Outra variável, que contribui ara o aumento da resistência à erosão, é a cobertura vegetal da margem e a densidade e profundidade de raízes existentes nas margens.

$\mathrm{Na}$ área estudada (segmento superior) constatou-se que o principal mecanismo que atua na erosão marginal é a corrasão, onde a base das margens no atrito com a ação da água, provoca o solapamento e consequentemente a queda de blocos como pode ser observado na figura 3. Em relação ao segmento inferior as margens são constituídas basicamente de material argiloso por estar situada na área do pantanal, neste caso os baixos valores de erosão marginal encontrada se deve a constituição granulométrica das margens, mudança no padrão do canal e diminuição da velocidade de fluxo.
Constatou-se a partir dos dados apresentados na tabela 1 que há grande deposição de sedimentos no canal, o que motiva a dragagem para manter navegabilidade. Apesar de todo o segmento estudado apresentar valores na taxa de erosão menores em relação a deposição, esse fator pode ser explicado pela fato de ter sido utilizado imagens de períodos diferentes e a cota do rio não ser a mesma, haja visto que a cota em 08/08/1984 (2,44m) e em 30/07/2003 $(1,74 \mathrm{~m})$ apresentando uma diferença de $0,70 \mathrm{~cm}$ o que pode ter influenciado nos valores da deposição.

CONCLUSÃO A abordagem realizada nesse trabalho procurou avaliar a erosão marginal no rio Paraguai na região de Cáceres-MT, e as formas dos processos erosivos e sedimentares. Esta necessidade surgiu em virtude da falta de estudos na área e que a partir dos levantamentos efetuados até agora foi possível chegar às seguintes conclusões:

$\mathrm{O}$ rio Paraguai possui um processo erosivo intenso e que no caso estas formas são atribuídas à queda de blocos e a desmoronamentos causados pelo solapamento da parte baixa da margem, resultante da corrasão, da ação hidráulica da água, e da ação das ondas provocadas pelos barcos.

As medições das margens dos rios têm como objetivo avaliar as taxas de erosão e migração lateral do canal, para isso utiliza-se diversas técnicas para o monitoramento. Entre essas técnicas uma das mais utilizadas é o método de pinos em que consiste a fixação de pinos de aço nas margens do rio. No caso do rio Paraguai Souza (2003) utilizou esse método para monitoramento da erosão entre a cidade de Cáceres e a Ilha Taiamã. De acordo com a autora em suas conclusões recomenda a utilização de outros métodos para o estudo da erosão marginal em decorrência das características do rio Paraguai.

A ineficiência do método de pinos no rio Paraguai, deve-se ao fato de que as margens do rio são
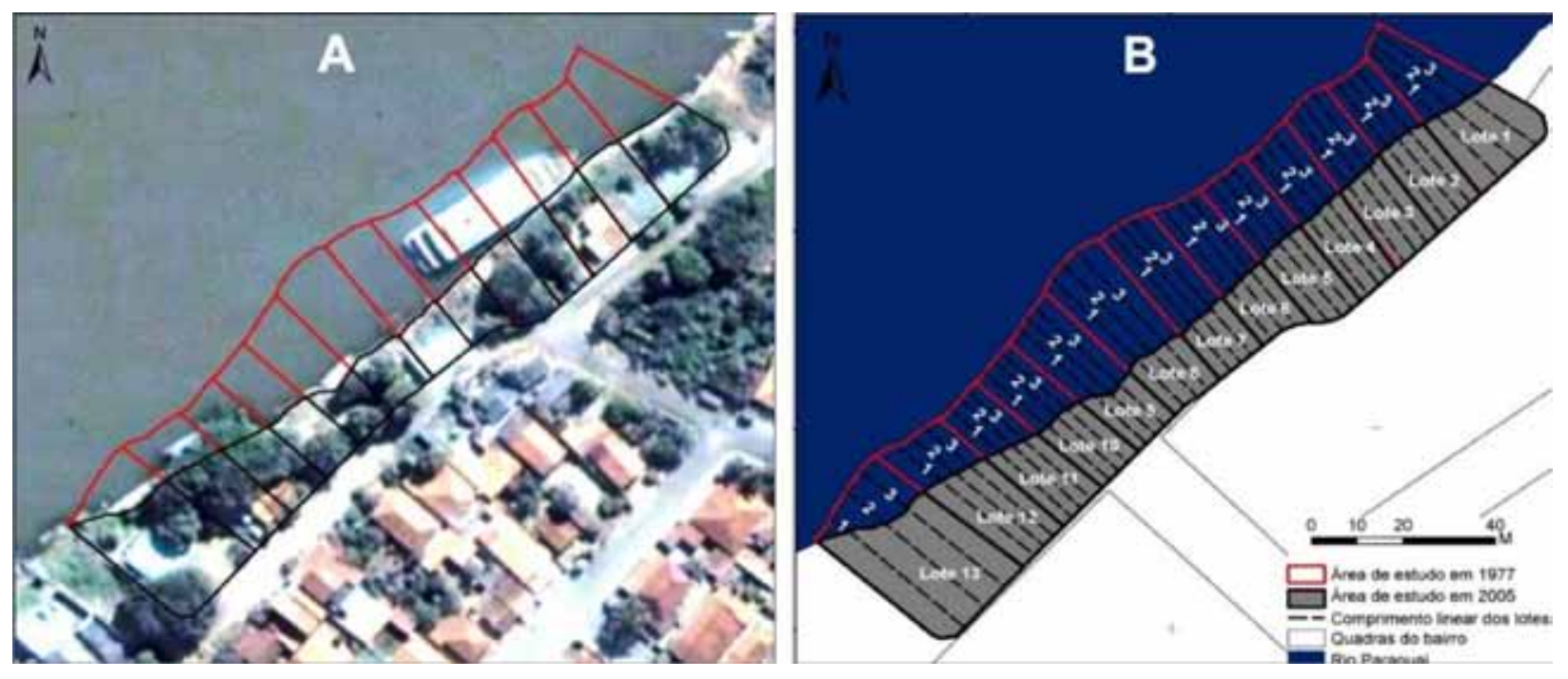

Figura 6 - Impactos causados pela erosão marginal no Bairro São Miguel - Cáceres/MT. Terrenos residenciais do bairro São Miguel atingidos pela erosão marginal do rio Paraguai (A) e a área de estudo em 1977 e 2005 após 28 anos (B) Fonte: Imagem Quick Bird (2005) (Fonte Silva et al. 2008). 
constituídas basicamente de areia e de difícil monitoramento utilizando esse método, pois no período de águas altas eles são retirados pela correnteza e muitas vezes por pessoas que utilizam as margens do rio para pescaria. Em virtude desse fator a utilização de técnicas de sensoriamento remoto para estimativa da erosão marginal do rio Paraguai, apresentou um resultado satisfatório, comparado aos métodos tradicionais de pinos e estacas. Apesar de ter alcançado bons resultados no futuro utilização de imagens de alta resolução poderá fornecer um resultado mais satisfatório.

Com os resultados alcançados utilizando imagens de satélites, chega-se a conclusão de que o período analisado os valores deposição foram maiores que os valores de erosão. Uma das explicações pode ser em decorrência da diferença da cota do rio referente aos anos de 1984 e 2003.

Para a adequada compreensão dos processos erosivos no rio Paraguai se faz necessário um monitora- mento mais sistemático (balanço de massa) para avaliar se o sistema é erosivo ou deposicional, haja vista que a partir do cruzamento das imagens as taxas de deposição foram maiores que as taxas de erosão. Conforme discutido anteriormente a taxa de deposição pode ter sido maior em decorrência das diferenças na cota do rio, que variou $0,70 \mathrm{~cm}$ de um periodo para o outro.

Numa região que vem se transformando economicamente e que tem no rio Paraguai uma importante via de escoamento através da hidrovia Paraguai-Paraná. As evidencias aqui relacionadas em curto prazo podem provocar grandes modificações no sistema como que já vem ocorrendo na cidade de Cáceres e também os impactos sentido pela navegação no segmento inferior devido a redução da profundidade do canal. É necessário o desenvolvimento de projetos que contemplem estudos sistemáticos para um melhor conhecimento hidrológico, ambiental e desta forma propor uma melhor forma de ocupação da área.

\section{Referências}

AGÊNCIA NACIONAL DE ÁGUAS (ANA). 2004. Implementação de Práticas de Gerenciamento Integrado de Bacia Hidrográfica para o Pantanal e Bacia do Alto Paraguai ANA/GEF/PNUMA/OEA: Programa de Ações Estratégicas para o Gerenciamento Integrado do Pantanal e Bacia do Alto Paraguai. Brasília, Relatório Final/ Agência Nacional de Águas.

Assine M.L. \& Silva A. 2009. Contrasting fluvial styles of the Paraguay river in the northwestern border of the Pantanal wetland, Brazil. Geomorphology, doi:10.1016/j. geomorph.2009.03.012.

Borges C.Z. 2004. A erosão marginal no rio Paraná após a conclusão de Porto Primavera. Dissertação de Mestrado, PGE, Universidade Estadual de Maringá.

Fernandez O.V.Q. 1990. Mudanças no canal fluvial do rio Paraná e processos de erosão nas margens; Região de Porto Rico-PR. Rio Claro, Dissertação de Mestrado, UNESP, Instituto de Geociências e Ciências Naturais, p.85.

Hooke J.M. 1979. An Analysis of the Processes of River Bank Erosion. Journal of Hydrology, 42:39-62.

Hooke J.M. 1980. Magnitude and Distribution of Rates of River Bank Erosion. Earth Surface Processes, 5:143-157.

Ministério dos Recursos Hídricos e da Amazônia Legal. 1997. Plano de Conservação da Bacia do Alto Paraguai-Pantanal (PCBAP). Diagnóstico do Meio Físico e Biótico. Brasília, vol. 2, p. 1349.

Moreira M.A. 2003. Fundamentos do sensoriamento remoto e metodologias de aplicação. 2a. ed., Viçosa: UFV.

Silva A., Souza C.A., Zani H., Freitas D.R. 2007. Avaliação da erosão na margem direita do rio Paraguai a jusante da praia do Julião: município de Cáceres-MT. Rev. Geogr. Acadêmica, 1(1-xii.2007):5-19

Silva A., Neves S.M.A.S., Neves R.J. 2008. Sensoriamento Remoto Aplicado ao Estudo da Erosão Marginal do rio ParaguaiI: Bairro Miguel em Cáceres-MT- Brasil. Revista Geográfica Acadêmica, 2(3):19-27.

Silva A., Souza Filho E.E., Cunha S.B. 2008. Padrões de ca- nal do rio Paraguai na região de Cáceres (MT). Revista Brasileira de Geociências, 38(1):169-179.

Silva A., Assine M.L., Zani H., Souza Filho E.E. de, Araujo B.C. 2007. Compartimentação Geomorfológica do rio Paraguai na borda norte do Pantanal Mato-Grossense, região de Cáceres-MT. Revista Brasileira de Cartografia, 59(01):73-81.

Silva A. 2006. Padrões de Canal do rio Paraguai na região de Cáceres-MT. Dissertação de Mestrado, Programa de Pós-Graduação em Geografia - Universidade Estadual de Maringá, 80 p.

Souza C.A. \& Cunha S.B. 2007. Pantanal de Cáceres - MT: Dinâmica das Margens do Rio Paraguai. Revista Eletrônica da Associação dos Geógrafos Brasileiros, Seção Três Lagoas, IV:18-41.

Souza C.A. 2004. Dinâmica do Corredor Fluvial do rio Paraguai entre a cidade de Cáceres e a Estação Ecológica da Ilha de Taiamã - MT. Tese de Doutoramento, UFRJ.

Souza Filho E.E. \& Stevaux J.C. 2004. Geology and Geomorphology of the Baía-Curutuba-Ivinheima River complex. In: Thomaz S.M., Agostinho A.A., Hahn N.S. (ed.) The Upper Paraná River and its Floodplain: Physical aspects, Ecology and Conservation. Leiden, The Netherlands, Blackhuys Publishers, p. 1-30.

Souza Filho E.E. \& Silva A. 2005. Evidences of Recent Tectonic Control Over the High Paraguai River Channel, Close to Cáceres City (MT) In: International Symposium an Land Degradation and Desertification, UrbelândiaMG, p. 37.

Tuysuz O. 2005. Jeomorfoloji de Seçme Konular Ders Notlari Ana Sayjasi; Fluvial Systems. Disponível em: <http:// www.eies.itur.edu.tr/> Acesso em: 08 dez. 2005.

Manuscrito ID 11039

Submetido em 27 de março de 2008 Aceito em 26 de maio de 2011 